\title{
Crustal structure of northeastern Tibetan plateau and Ordos block: Waveform interpretation of the Maqen-Jingbian seismic refraction profile*
}

\author{
Fuyun Wang * Hong Shang and Xiankang Zhang \\ Geophysical Exploration Center, China Earthquake Administration, Zhengzhou 450002, China
}

\begin{abstract}
The Maqen-Jingbian wide-angle seismic reflection and refraction experiment was carried out in 1998, which aims at determining detailed structure in the crust and top of the upper mantle and understanding structural relation between the northeastern Tibetan plateau and the Ordos block. The 1-D crustal models inferred by waveform inversion show strong variations in crustal structure, which can be classified into four different types: (1) an Ordos platform with the Proterozoic crust and two high-velocity layers in the northeast section, (2) a transitional crust between the northeastern Tibetan plateau and the Ordos block across the Haiyuan earthquake zone, (3) the Qilian orogenic zone in the central part, and (4) the Qinling orogenic zone in the southwestern section. The Moho depth increases from $\sim 42 \mathrm{~km}$ to $\sim 62 \mathrm{~km}$ from the NE part to the SW part of the profile. The crystalline crust consists of the upper crust and lower crust in northeastern Tibetan plateau. There is an obviously low P-wave velocity layer dipping northeastward, which is $12-13 \mathrm{~km}$ thick, at the bottom of the upper crust in Qinling orogenic zone and Haiyuan earthquake zone. The lower crust is characterized by alternating high and low P-wave velocity layers. Beneath Ordos block, i.e., the NE part of the profile, the crust shows quite a smooth increase in P-wave velocity down to the Moho at a depth of about $42 \mathrm{~km}$.
\end{abstract}

Key words: crustal structure; northeastern Tibetan plateau; Ordos block; waveform interpretation; seismic refraction CLC number: P315.2 Document code: A

\section{Introduction}

Nowhere does active overthrusting spread over a greater surface area than in the NE corner of Tibetan plateau. To the south and north, this broad region of coeval mountain building is limited by the Kunlun and Altyn Tagh-Haiyuan fault systems, respectively. All the large, 200-to-600-km-long, parallel $\left(\mathrm{N} 120^{\circ} \mathrm{E}\right)$ mountain ranges in between, from the eastern Kunlun to the Qilianshan, appear to grow as ramp anticlines of crustal scale, and most north-facing range-fronts are bounded by active thrusts (Tapponnier et al, 2001), whereas the Ordos block is a hard, good-whole block within which there are hardly any active tectonic activities or earthquakes above moderate magnitude.

A more thorough knowledge of subsurface structures of the NE corner of Tibet and Ordos block and the relation between shallow and deep tectonics is needed to

\footnotetext{
* Received 20 April 2009; accepted in revised form 13 July 2009; published 10 August 2009.

^ Corresponding author. e-mail: fuyunwang@x263.net
}

help us understand how they interact on each other, how the NE corner of Tibet rises and grows, and how the earthquakes prepare and occur in this region.

Crustal structure models based on earthquake tomography in the NE corner of Tibetan plateau (Zhang et al, 1998; Zhou et al, 2006) are too general to reveal some important details, due to the sparse permanent seismographic stations and the imprecise locations of earthquakes. Structure models based on seismic exploration and structural geology are limited in depth resolution. We need to understand the subdivision of the crust into blocks, the properties of the blocks, and how they are coupled. Such knowledge requires us to probe well below Moho depth, at least into all contributing structures.

To study the crustal structures of the NE corner of Tibet and Ordos, a 1 000-km-long deep seismic sounding profile was carried out along the line of Maqen-LanzhouJingbian (Figure 1), on which twelve explosions were triggered at nine shot points and 200 three-component seismographs were deployed. Li et al (2002) gave a preliminary model of the crust by a ray-tracing method. Zhang et al (2003) compared the crustal structures of the 
corner of the NE Tibetan plateau, Ordos block with the structure of the great earthquake area of Tangshan. In this paper, we present the images of 1-D crust and upper mantle from the NE corner of Tibetan plateau to Ordos block by modeling both refraction and reflection waveform data.

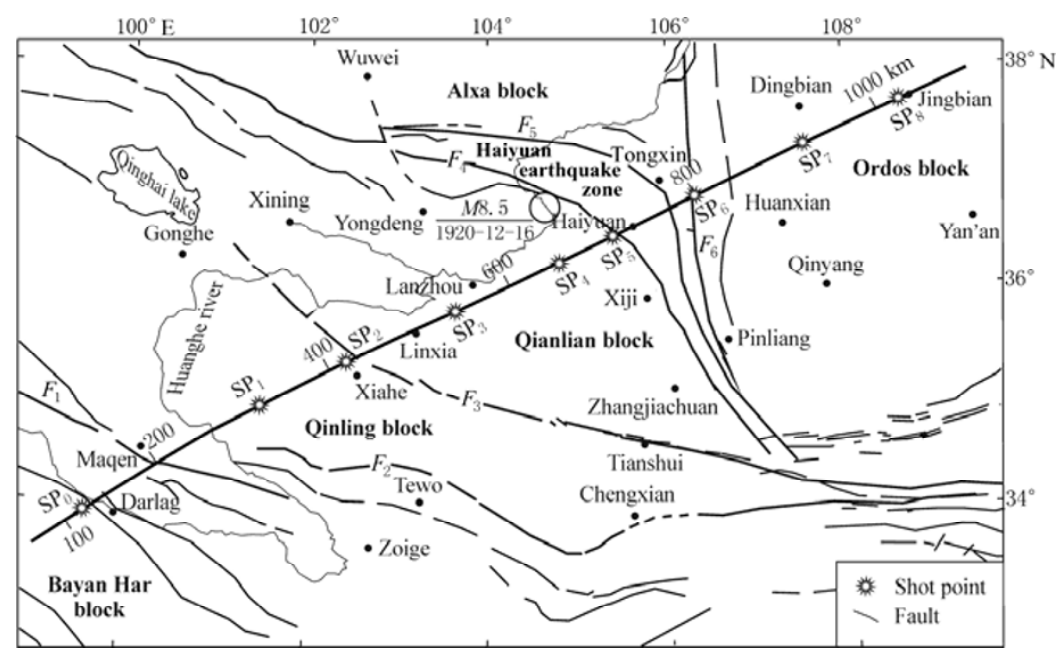

Figure 1 Profile location and geological setting of the studied area. $F_{1}$. Maqen fault; $F_{2}$. Zhouqu-Liangdang fault; $F_{3}$. North edge fault of Qinling axis; $F_{4}$. West Huashan-Liupanshan fault; $F_{5}$. North piedmont of Xiangshan-Liwangpu fault; $F_{6}$. Qingtongxia-Guyuan fault.

\section{Previous geophysical investigations}

The NE corner of Tibetan plateau and Ordos region have been studied with a variety of geophysical methods at relatively low resolution. Early deep seismic sounding studies were performed along Jingtai-Baiyin profile (Zeng et al, 1965), Menyuan-Pingliang-Weinan profile (Zhang et al, 1985), Zhengzhou-Yinchuan profile (Sun et al, 1993), Lingtai-Amqog profile (Min et al, 1991) and Chengxian-Xiji profile (Li et al, 1991). The results in these studies indicate that the crustal thickness varies between 40-42 $\mathrm{km}$ within Ordos, 48-52 $\mathrm{km}$ in the east part of Qilian and Qinling blocks, and 58-62 km in the west part of Qilian and Qinling blocks.

The ray-tracing and complexity coefficient models for Maqen-Jingbian deep seismic sounding profile show that the crust consists of the upper and lower parts, each of which contains a number of secondary interfaces. The lower crust becomes gradually thicker from northeast to southwest. The number of reflective horizons becomes gradually larger and the average crustal velocity becomes gradually lower. The complexity coefficients of $\mathrm{PmP}$ wave in Haiyuan and in the west of Zekog region are much larger than those in other parts ( $\mathrm{Li}$ et al, 2002; Zhang et al, 2003).

Zhang et al (1979), Wang (1984) and Zhang et al (2004) obtained the crust thicknesses of about $50 \mathrm{~km}$ in southeastern Gansu area and $58 \mathrm{~km}$ in eastern Qinghai area. The average velocities of $v_{\mathrm{P}}$ and $v_{\mathrm{S}}$ are $(6.17 \pm 0.19)$ $\mathrm{km} / \mathrm{s}$ and $(3.58 \pm 0.08) \mathrm{km} / \mathrm{s}$, respectively. The average velocity of $v_{\mathrm{Pn}}$ is $(8.08(8.17 ?) \pm 0.07) \mathrm{km} / \mathrm{s}$.

\section{P-wave field}

Maqen-Lanzhou-Jingbian profile starts at Jingbian county of Shanxi province, through Tongxin and Haiyuan counties in Ningxia Hui autonomous region, Huining county, Lanzhou city and Xiahe county in Gansu province, Maqen city in Qinghai province, and ends at Darlag county in Qinghai province. The receiver spacing and shot spacing are $1-3 \mathrm{~km}$ and $110 \mathrm{~km}$, respectively. The twelve explosions at nine shot points range in size from $1500 \mathrm{~kg}$ to $3000 \mathrm{~kg}$.

According to kinematic and dynamic characteristics of wave groups from the crystalline crust and crust-mantle boundary, these record sections may be divided into four types which relate to geologic tectonic units: an Ordos platform, a transitional crust between the northeastern Tibetan plateau and the Ordos block, the Qilian orogenic zone in the central part and the Qinling orogenic zone in the southwestern section. The $\mathrm{P}$ wave field for $\mathrm{SP}_{0}$ shot in Qinling block has three main features: (1) low apparent velocity of the first arrival Pg wave group, ending at source-receiver offset of 100-120 $\mathrm{km}$, (2) the strongest energy, long-wavetrain phase in all 
phases of record section within source-receiver offsets 80-180 km from the middle crust, and (3) a series of mutually interferential, low-apparent-velocity phases and indistinguishable Moho reflection at source-receiver offset over $200 \mathrm{~km}$ (Figure 2a). For $\mathrm{SP}_{2}$ shot (northeastward), the apparent velocity of Pg wave is about 6 $\mathrm{km} / \mathrm{s}$ and its traveltime curve has a sawtooth-like feature. There is a clear phase from the middle crust, and the

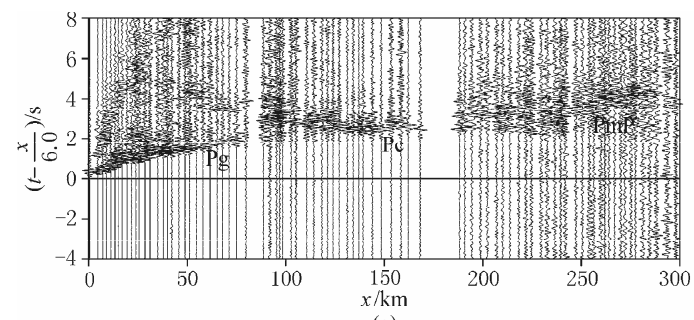

(a)

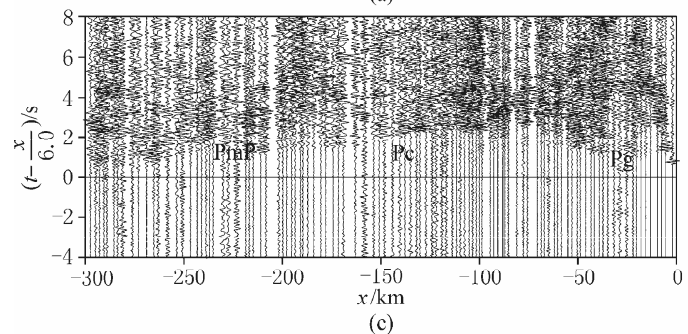

PmP phase from the crust-mantle boundary is distinguishable (Figure 2b). At the juncture of Ordos block and Tibetan plateau, these record sections are similar to those in Qinling block, but the PmP phase is distinguishable (Figure 2c). At Ordos block, the Pg, PmP, and Pn waves of the record sections are clearly distinguishable and have very short wavetrain (Figure $2 \mathrm{~d}$ ).

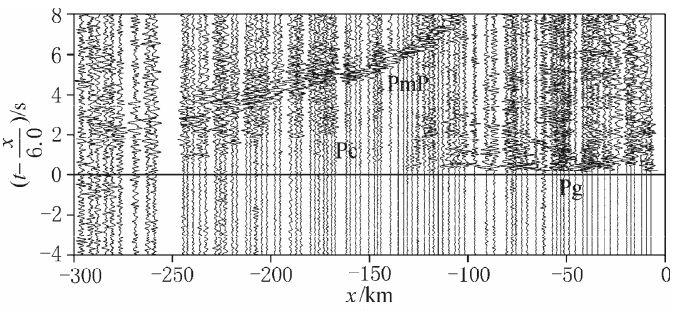

(b)

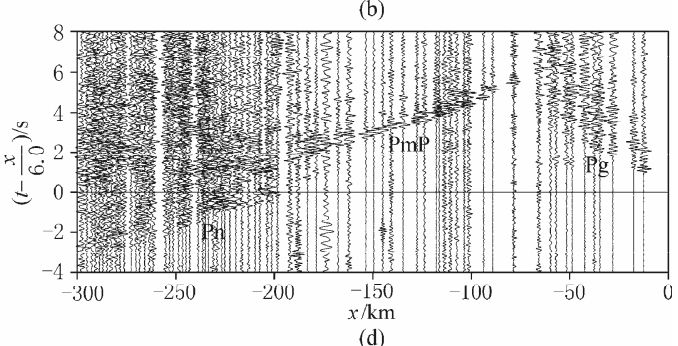

(d)

Figure 2 Characteristics of record sections reflecting Qinling (a), Qilian (b), Ordos (d) blocks and the transitional zone between northeastern Tibet plateau and Ordos block (c).

\section{Inversion of $P$ waveform}

A genetic algorithm is applied to the inversion of $\mathrm{P}$ waveform in Maqen-Lanzhou-Jingbian seismic profile (Wang and Zhang, 2006). The method involves search algorithms based on the mechanism of natural selection and natural genetics. Unlike local techniques, such as damped least squares or conjugate gradient, genetic algorithms avoid all use of curvature information on the objective function. This means that they do not require any derivative information and therefore one can use any type of misfit function equally well. Most iterative methods work with a single model and find improvements by perturbing it in some fashion. Genetic algorithms, however, work with a group of models simultaneously and use stochastic processes to guide the search for an optimal solution. They combine survival of the fittest among string structures with a structured yet randomized information exchange to form a search algorithm with some of the innovative flair of human search. In each generation, a new set of binary string representations of the parameter decimal models is created using bits and pieces of the fittest of the old, and an occasional new part is tried for good measure. While randomized, genetic algorithms are no simple random walk. They efficiently exploit historical information to speculate on new search points with expected improved performance.

We select the high signal-to-noise $\mathrm{P}$-wave data from raw records (Table 1) according to the time window arriving for $\mathrm{P}$ wave. Source time function is taken from waveform of the Pg wave with proper shot-detector distance, distinct waveform, sharp initiation and rapid attenuation, based on Mellman (1980). It spontaneously contains instrument response.

The number of layers in the model for each shot (Table 1) is determined by seismic phases and waveform complexity. Generally, the more phases there are, the larger number of layers there will be. Model parameters are the layer's thickness and velocity. According to our existing knowledge of crustal structure, the selected search range of layer thickness is $0-3 \mathrm{~km}$ and the selected search range of layer velocity is $5.4-6.4 \mathrm{~km} / \mathrm{s}$ in the upper crust, $5.6-7.0 \mathrm{~km} / \mathrm{s}$ in the middle crust, $6.0-7.4 \mathrm{~km} / \mathrm{s}$ in the lower crust and $7.6-8.3 \mathrm{~km} / \mathrm{s}$ in the top of upper mantle.

The control parameters of genetic algorithm are: 
population size $Q=46$, probability of crossover $P_{\mathrm{c}}=$ 0.98 , probability of mutation $P_{\mathrm{m}}=0.002$ and the number of iterations 200. After 200 iterations, the initial and final objective function values for the nine shots are listed in Table 1.

Figures 3, 4, 5 and 6 are the typical seismic record section, synthetic section from the optimal inversion model, and the optimal inversion model reflecting Qinling, Qilian, Ordos blocks and the transitional zone between northeastern Tibetan plateau and Ordos block, respectively.
Table 1 Number of records selected, model layers and the initialfinal objective values for the inversion of the nine shots

\begin{tabular}{ccccc}
\hline Shot & $\begin{array}{c}\text { Record } \\
\text { number }\end{array}$ & $\begin{array}{c}\text { Layer } \\
\text { number }\end{array}$ & $\begin{array}{c}\text { Initial objective } \\
\text { value }\end{array}$ & $\begin{array}{c}\text { Final objective } \\
\text { value }\end{array}$ \\
\hline $\mathrm{SP}_{0}$ & 89 & 43 & 88.354 & 80.027 \\
$\mathrm{SP}_{1}$ & 78 & 34 & 71.875 & 60.951 \\
$\mathrm{SP}_{2}$ & 80 & 40 & 74.626 & 63.237 \\
$\mathrm{SP}_{3}$ & 80 & 29 & 79.125 & 74.450 \\
$\mathrm{SP}_{4}$ & 75 & 37 & 70.219 & 65.217 \\
$\mathrm{SP}_{5}$ & 67 & 39 & 65.172 & 58.221 \\
$\mathrm{SP}_{6}$ & 60 & 38 & 56.582 & 47.521 \\
$\mathrm{SP}_{7}$ & 65 & 41 & 62.732 & 48.321 \\
$\mathrm{SP}_{8}$ & 63 & 34 & 61.682 & 57.261 \\
\hline
\end{tabular}

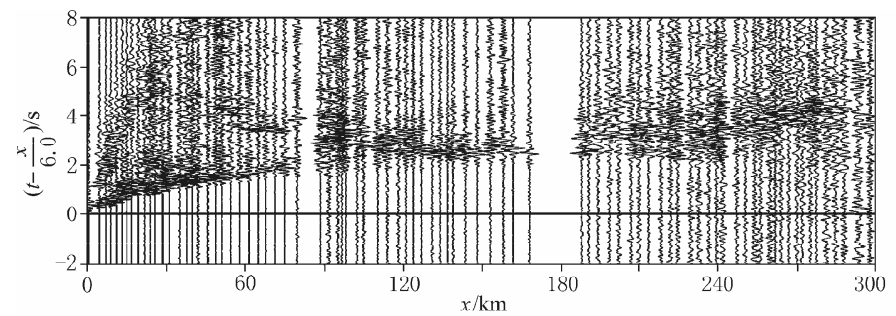

$x / \mathrm{km}$
(a)

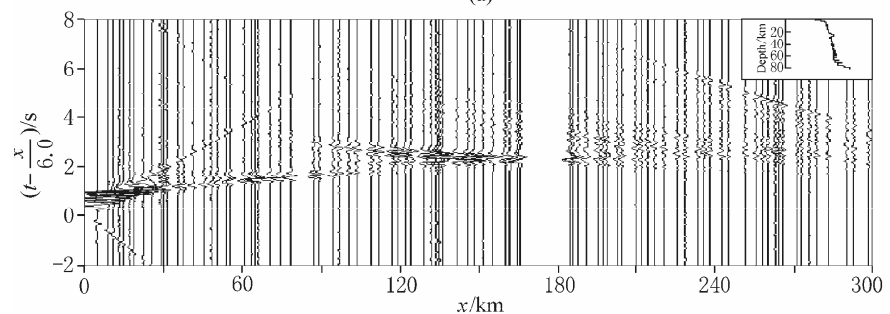

(b)

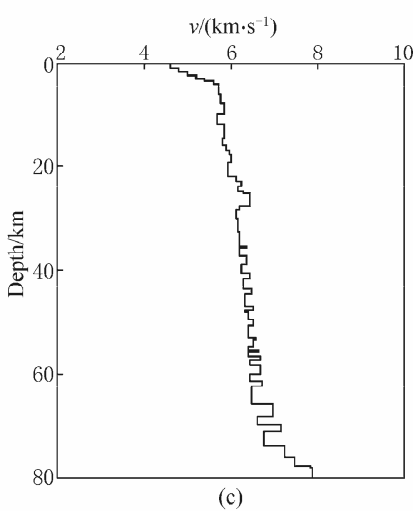

Figure 3 Seismic record section (a), synthetic section (b) of the optimal inversion model and the optimal inversion model (c) reflecting Qinling block structure for the $\mathrm{SP}_{0}$ shot. The strongest phase from interfaces in the middle crust is clearly distinguished and there are distinct complex reflectivity phases from the lower crust and crust-mantle boundary. This implies that there is a strong reflection layer or interface in the middle crust; the lower crust and crust-mantle boundary are layered structures with alternating high and low velocities.

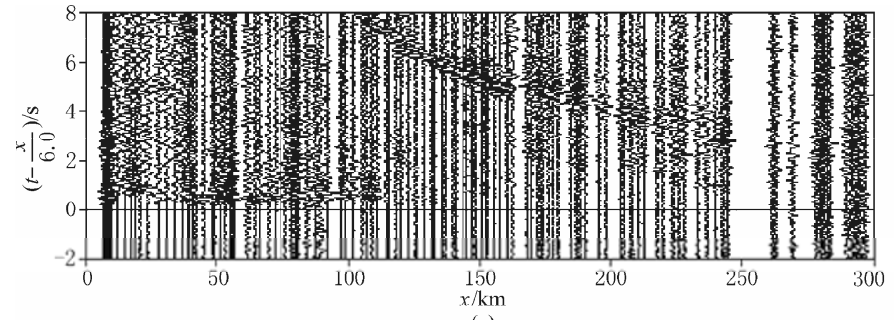

(a)

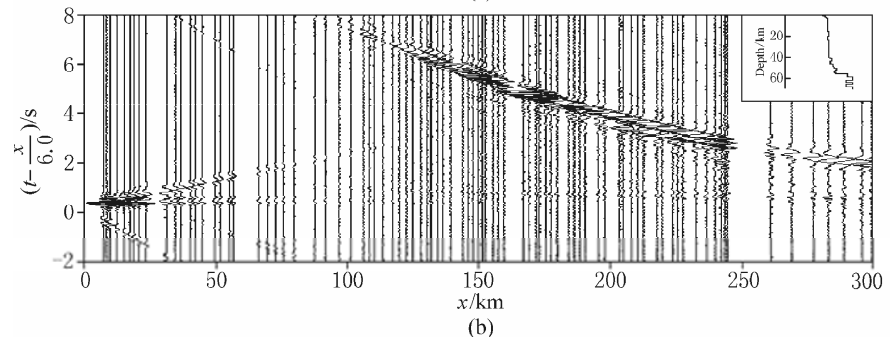

(b)

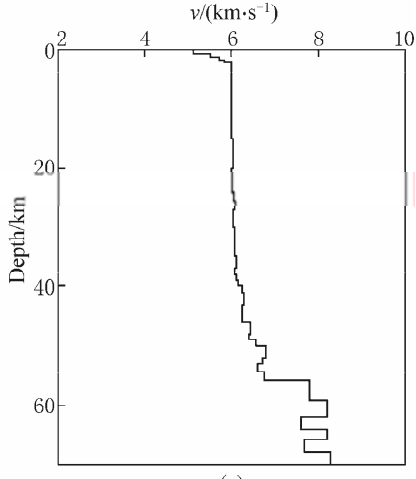

(c)

Figure 4 Seismic record section (a), synthetic section (b) of the optimal inversion model and the optimal inversion model (c) reflecting Qilian block structure for the $\mathrm{SP}_{3}$ shot. There are weak complex reflections from the lower crust and the strongest phase from Moho. 


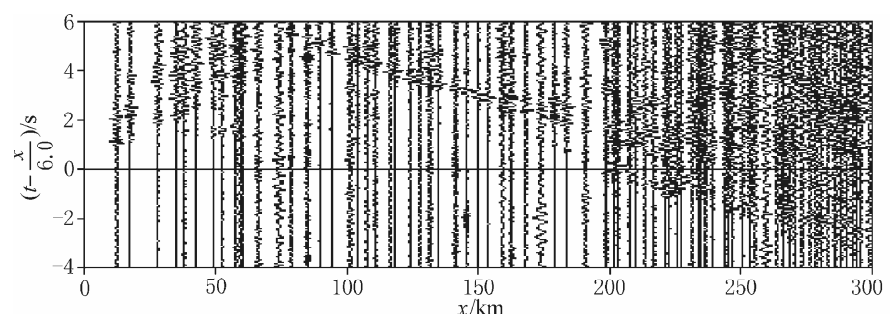

(a)
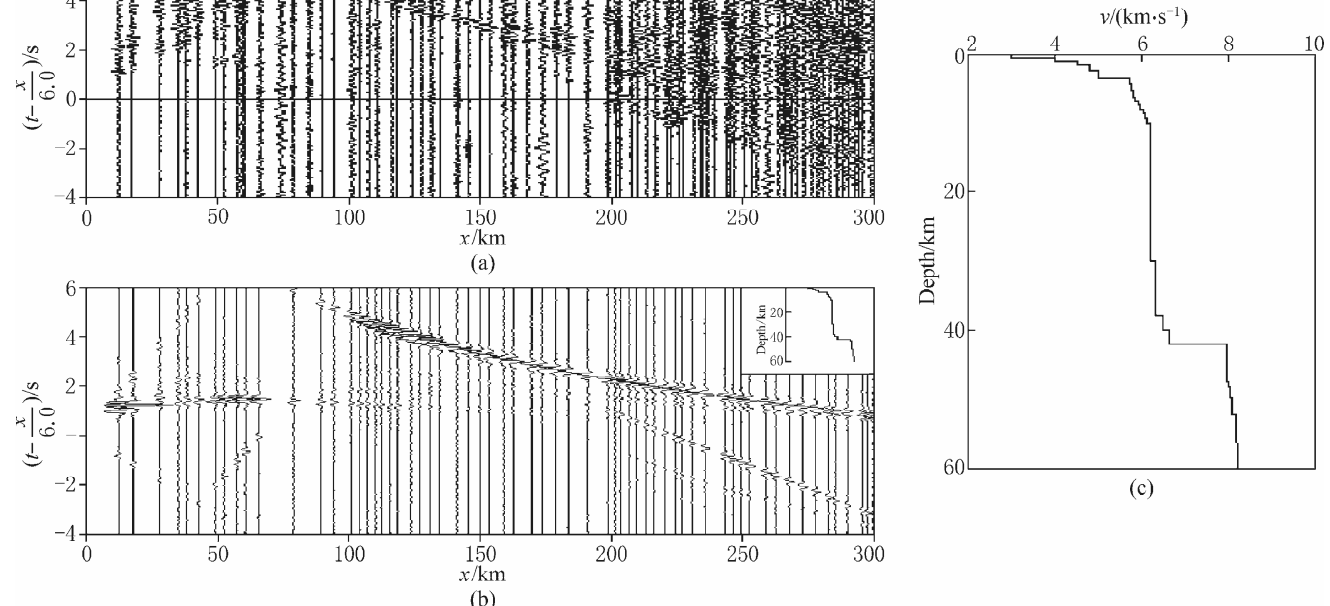

(b)

Figure 5 Seismic record section (a), synthetic section (b) of the optimal inversion model and the optimal inversion model (c) reflecting Ordos block structure for $\mathrm{SP}_{8}$ shot. There are very clear $\mathrm{PmP}$ and $\mathrm{Pn}$ phases.

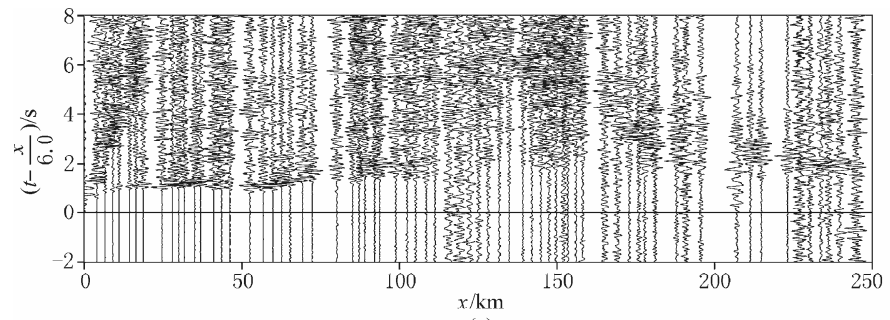

(a)

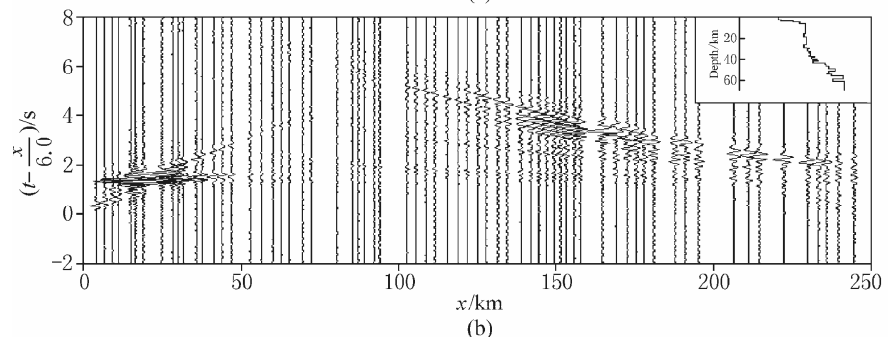

(b)

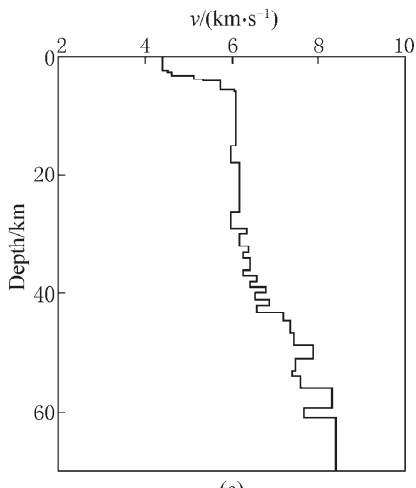

(c)

Figure 6 Seismic record section (a), synthetic section (b) of the optimal inversion model and the optimal inversion model (c) reflecting transitional zone structure between northeastern corner of Tibetan plateau and Ordos block for the $\mathrm{SP}_{4}$ shot. Seismic record section is characterized by reflectivity of the upper crust and crust-mantle boundary.

\section{Results}

Seismic waveform fitting of $\mathrm{SP}_{0}, \mathrm{SP}_{1}$ and $\mathrm{SP}_{2}$ (southwestward) shots reveals that crustal structure of Qinling block has the feature of active crust. Surface layer of the upper crust is a strong positive velocity gradient layer within $0-4 \mathrm{~km}$ depth. There are a weak positive velocity gradient layer within $4-16 \mathrm{~km}$ depth, an obviously low velocity layer between 10-30 km (Figure 7) and a layer with alternating high and low velocities under $25-30 \mathrm{~km}$ depth. The average velocity of the crust is relatively low. The Moho discontinuity is about 65, 62 and $58 \mathrm{~km}$ deep for the $\mathrm{SP}_{0}, \mathrm{SP}_{1}$ and $\mathrm{SP}_{2}$ shots, respec- tively. Velocity of the topmost upper mantle is around $7.8 \mathrm{~km} / \mathrm{s}$.

The crustal structure of the Qilian block is relatively stable. The crust consists of two layers and the crustal thickness is around $56-58 \mathrm{~km}$. There exists a weak low-velocity layer with relatively small size (Figure 7) in lower part of the upper crust. The covering stratum is fairly thin. The low velocity zone of the surface layer is about $1-2 \mathrm{~km}$ thick. The upper crust is relatively homogeneous in velocity and the lower crust is featured by a layer with moderately variable alternating high and low velocities. The velocity gradient becomes larger above the Moho discontinuity, which is approxi- 
mately a first-order velocity discontinuity. A layer with alternating high and low velocities exists in the topmost upper mantle, where the average velocity is $7.9-8.1$ $\mathrm{km} / \mathrm{s}$.

Waveform inversion of the $\mathrm{SP}_{4}, \mathrm{SP}_{5}$ and $\mathrm{SP}_{6}$ shots reveals that crustal structure of the block boundary also shows active features. Surface layer of the upper crust is a strong positive velocity gradient layer with a thickness of $0-5 \mathrm{~km}$. There is a homogeneous layer between $5 \mathrm{~km}$ and $16 \mathrm{~km}$ depths, beneath which a $5-\mathrm{km}$-thick low velocity layer is obviously located. The middle crust is a layer with alternating high and low velocities, and the lower crust is a positive velocity gradient layer about 10 $\mathrm{km}$ in thickness. The Moho discontinuity is about $58 \mathrm{~km}$ deep. The topmost upper mantle has a velocity of around $7.9 \mathrm{~km} / \mathrm{s}$ and it also assumes a structural form of alternating high and low velocities (Figure 7).

Under the $\sim 42-\mathrm{km}$-thick crust of Ordos block, which is not distinctly layered, the sub-Moho velocities are about $8.1 \mathrm{~km}$. Velocity of the crystalline crust increases with depth from $5.8 \mathrm{~km} / \mathrm{s}$ at top of the basement to $6.8 \mathrm{~km} / \mathrm{s}$ at the Moho (Figure 7).

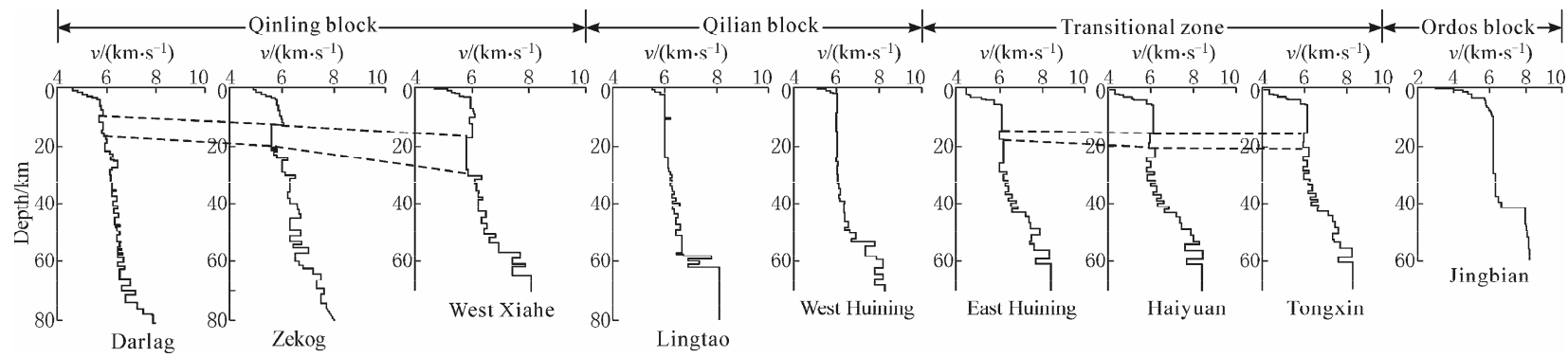

Figure 7 1-D velocity-depth functions along the Darlag-Lanzhou-Jingbian profile. Dashed lines represent the low velocity zone.

\section{Discussion and conclusions}

Several 1-D seismic velocity models for different sections, inferred from $\mathrm{P}$ waveform fitting for the Maqen-Lanzhou-Jingbian DSS profile, have been presented, which reveals new features for the area.

There clearly exist a 12-km-thick low velocity layer dipping northeastward between $16 \mathrm{~km}$ and $30 \mathrm{~km}$ depth in the Qinling block, and a 5-km-thick low velocity layer between $17 \mathrm{~km}$ and $22 \mathrm{~km}$ depth in the transitional zone between the northeastern margin of the Tibetan plateau and the Ordos block. We infer that the two low velocity layers may be the major detachments at the bottom of the upper crust. The southwestern major detachment, dipping northeastward, possibly connects the shallow Maqen fault and the northern marginal fault of Qinling, while the northeastern detachment possibly connects the shallow western Huashan-Liupanshan fault, the northern Xiangshan-Liwangpu piedmont fault and the Qingtongxia-Guyuan fault. This hypothesis is supported by the low apparent velocity of reflected wave from the bottom of upper crust (Figure 3 and Figure 5). At the two depth ranges of $16-30 \mathrm{~km}$ and $17-22 \mathrm{~km}$, the two detachments converge to the bottom of the brittle crustal zone, and may represent the decoupling zones between the upper and lower crusts (Figure 7).
Under the Qinling block, the transitional zone between NE margin of Tibetan plateau and the Ordos block, the middle and lower crust and the top of the upper mantle are characterized by two layers with alternating high and low velocities. We infer that such a feature of the crust and mantle structure may result from the northeastward flow of the lower crust and upper mantle material. This interpretation is consistent with the complicated reflections from lower crust and upper mantle at the two regions (Figure 3 and Figure 5).

Acknowledgments This study is supported by National Natural Science Foundation of China (Grant No. 90814012). Contribution No. 200909, Geophysical Exploration Center, China Earthquake Administration (CEA). The authors are grateful to the field crew of Geophysical Exploration Center, CEA, for collecting the Maqen-Jingbian wide-angle seismic reflection and refraction data, and to Dr. Xuyao Zheng and Ms. Yuling Zuo from Institute of Geophysics of CEA for improving the paper. Thanks are also given to the two anonymous reviewers for valuable suggestions and comments.

\section{References}

Li Q H, Guo J K, Zhou M D, Wei D Q, Fan B and Hou X J (1991). The crustal velocity structure from Chengxian to Xiji. Northwestern Seismological Journal 13(Suppl): 37-43 (in Chinese with English abstract).

Li S L, Zhang X K, Zhang C K, Zhao J R and Cheng S X (2002). A preliminary study on the crustal velocity structure of Maqin-Lanzhou-Jingbian by 
means of deep seismic sounding profile. Chinese $J$ Geophys 45(2): 210-217 (in Chinese with English abstract).

Mellman G R (1980). A method of body-wave waveform inversion for the determination of earth structure. Geophys $J$ R astr Soc 62: 481-504.

Min X Y, Zhou M D, Guo J K, Wei D Q, Zhang Y S, Hou X J and Song J (1991). The crustal velocity structure in Lingtai-Amuquhu profile. Northwestern Seismological Journal 13(Suppl): 29-36 (in Chinese with English abstract).

Sun W C, Xu J, Yang Z E, Zhu Z P, Song S Y and Zhang X K (1993). Geotransect From Shanghai Fengxian to Inner Mongolia Alxa. Seismological Press, Beijing, 19-37 (in Chinese).

Tapponnier P, Xu Z Q, Roger F, Meyer B, Arnaud N, Wittlinger G and Yang J S (2001). Oblique stepwise rise and growth of the Tibet Plateau. Science 294 $1671-1677$.

Wang F Y and Zhang X K (2006). Genetic algorithm in seismic waveform inversion and its application in deep seismic sounding data interpretation. Acta Seismological Sinica 19(2): 163-172.

Wang Z Y (1984). The layering crustal structure in Gansu Province. Northwestern Seismological Journal 6(3): 84-91 (in Chinese with English abstract).

Zeng R S, Teng J W and Kan R J (1965). The high velocity layer of the crust in Northwestern China. Chinese J Geophys 14(2): 94-106 (in Chinese with English abstract).
Zhang C, Zhang L, Deng Q Z and Ge J H (1979). The crustal thickness in Gansu Province and adjacent area. Northwestern Seismological Journal 1(2): 22-26 (in Chinese with English abstract).

Zhang S Q, Wu L J, Guo J M, Chen X B, Zhao J X, Ding W Y, Huang C L, Zhang C and Chen Z T (1985). The interpretation of Menyuan-Pingliang-Weinan deep seismic sounding data. Chinese J Geophys 28(5): 349-361 (in Chinese with English abstract).

Zhang X K, Li S L, Wang F Y, Jia S X and Fang S M (2003). Differences of crustal structures of northeastern edge of Tibet Plateau, Ordos and Tangshan earthquake region in North China - Results of deep seismic sounding. Seismology and Geology 25(1): 52-60 (in Chinese with English abstract).

Zhang Y S, Li Q H and Xu G M (1998). Combined inversion technique to study 3-D crustal velocity structure by using seismic traveltime and waveform (II) - Application. Northwestern Seismological Journal 20(3): 44-51 (in Chinese with English abstract).

Zhang Y S, Zhou M D, Rong D L, Zhang L G and Xu Z Q (2004). 3-D velocity structure in the central-eastern part of Qilianshan. Acta Seismologica Sinica 17(3): 272-281.

Zhou M D, Zhang Y S, Shi Y L, Zhang S X and Fan B (2006). Three-dimensional crustal velocity structure in the northeastern margin of the Qinghai-Tibetan Plateau. Northwestern Seismological Journal 28(1): 127-134 (in Chinese with English abstract). 